\title{
Societal Concerns with Biotechnology and Necessity of Regulations
}

\author{
Abu Sadat Mohammad Nurunnabi', Miliva Mozaffor'2, Mariya Tabassum ${ }^{3}$, Taohidur \\ Rahman Saikat ${ }^{4}$, Nahid Kabir ${ }^{5}$, Mohammad Akram Hossain ${ }^{6}$
}

1. Research Assistant, Bridgepoint Collaboratory for Research and Innovation, Bridgepoint Active Healthcare, Toronto, ON, Canada. Email: abu.nurunnabi@sinaihealthsystem.ca (corresponding author)

2. Clinician Researcher, Biomedical Research Foundation (BRF), Dhaka, \& Laboratory Consultant and Lecturer, Department of Biochemistry, Medical College for Women \& Hospital, Uttara, Dhaka-1230, Bangladesh. Email: miliva17@yahoo.com

3. Lecturer, Department of Biochemistry, Mugda Medical College, Dhaka-1214, Bangladesh. Email: drmariyatabassum@gmail.com

4. BSc (Hons.) student, Department of Biochemistry and Molecular Biology, Tejgaon College, Dhaka-1215, Bangladesh. Email: taohidurrahman9@gmail.com

5. MSc student, School of Environment and Life Sciences, Independent University, Bangladesh, Bashundhara, Dhaka-1212, Bangladesh. Email: nahidkabir@gmail.com

6. Professor and Head, Department of Microbiology and Mycology, National Institute of Preventive and Social Medicine (NIPSOM), Dhaka-1212, Bangladesh. Email: akram.prof@gmail.com

DOI: DOI: https://doi.org/10.3329/bioethics.v10i2.50660

\begin{abstract}
Biotechnology is the use of living systems and organisms to develop or make products, or any technological application that uses biological systems, living organisms or derivatives to make or modify products or processes for specific use. Biotechnology is a constantly evolving field of modern science. New tools and products developed by biotechnologists are useful in research, agriculture, industry and healthcare. Although it has many benefits including lowering our environmental footprint, and helping in diagnosis and treatment of diseases, it comes with its all-possible disadvantages. The four main societal concerns revolve around are ethical, safety, bioterrorism and environmental issues. This paper aims to describe those societal concerns raised by applications of biotechnology and possible regulations related to biotech innovations and policy implementation.
\end{abstract}

Key words: Biotechnology, societal concerns, ethical issues, laboratory safety, bioterrorism, environmental protection.

Introduction: People have been harnessing biological processes to improve their quality of life for some 10,000 years, beginning with the first agricultural communities. Approximately 6,000 years ago, humans began to tap the biological processes of microorganisms in order to make bread, alcoholic beverages, and cheese and to preserve dairy products ${ }^{1}$. Such processes are not what is meant today by biotechnology. Moreover, today's biotechnologies vary in application and complexity. The term 'biotechnology' first widely applied to the molecular and cellular technologies that was emerging in the 1960s and '70s. Genentech, a pharmaceutical company established in 1976 by Swanson and Boyer to commercialize the recombinant DNA 
technology, as pioneered by Boyer, Berg, and Cohen ${ }^{1}$. Early companies such as Genentech, Amgen, Biogen, Cetus, and Genex began by manufacturing genetically engineered substances primarily for medical and environmental uses ${ }^{1}$. Biotechnology is the use of living systems and organisms to develop or make products, or any technological application that uses biological systems, living organisms or derivatives to make or modify products or processes for specific use $^{2}$. New tools and products developed by biotechnologists are useful in research, agriculture, industry and healthcare. Innovations through biotechnology using organisms or their parts or products provide valuable substances or processes that have become essential in our day-to-day life. For example, production of human insulin in bacteria to treat type I diabetes mellitus without causing allergic reactions is a more modern example of biotechnology. Two widely used biotechnologies that manipulate genes are recombinant DNA technology, which endows single-celled organisms with novel characteristics using genes from other organisms, and transgenic technology, which creates multicellular organisms that bear genes from other types of organisms ${ }^{2}$. Very recent innovations are genetically modified (GM) fruits and vegetables, such as a type of corn that manufactures a bacterial insecticide, are termed as "transgenic plants" 3 . Thus, biotechnology use knowledge of biological sciences and advanced technologies to generate new and useful products and processes for the benefit of society. Living standards have risen alongside biotech innovation and economic growth in so many countries. Even when it comes to developing countries, biotechnologies and innovative solutions are helping to combat issues such as disease, hunger and poverty ${ }^{3}$. Although it has many benefits including lowering our environmental footprint, and helping in diagnosis and treatment of diseases, it comes with its all possible disadvantages ${ }^{4}$. Several ethical concerns such as informed consent, confidentiality, wellbeing of the subjects for research, equal access to the benefits of research, intellectual property rights, costs have come into the focus ${ }^{4-9}$. Human and laboratory safety issues are crucial as it is assumed that in future insects and plantdestroying bacteria or diseases may continue to evolve to give rise to superpests or 'superbugs' $10-12$. Moreover, there might be chances of outbreak of epidemics, due to faulty or erroneous handling of microorganisms or chemicals in the biotech laboratories $^{12.13}$. Relating this issue, major emphasis is on how to control bioterrorism using genetically engineered super pathogens, drugs or chemicals ${ }^{4,14-17}$. Environmental issues have also come to the forefront as GMOs are thought to be the organisms actually put the entire food supply at risk through the homogenization of plant life and the death of biodiversity ${ }^{18-21}$. Therefore, bioethics community stands for the safe regulation of potential benefits of innovations in biotechnology and for welfare of mankind as well as our environment, which has become crucial at the moment. This paper aims to describe those societal concerns raised by applications of biotechnology and possible safeguards related to biotech innovations and policy implementation. 
Societal Concerns: Today's social challenges are numerous, complex, and urgent, from ageing societies, climate change, to energy efficiency and security ${ }^{3,4}$. There is a wide consensus that the disconnection between economic growth and wellbeing is increasing. At the same time research and innovation have become one of the main engines of growth ${ }^{4}$. However, these two overarching trends have not yet been reconciled: there is a clear lack of exploitation of innovative solutions to address these social challenges ${ }^{4}$. Besides, biotechnology developments are often controversial because of the societal issues they raise. They frequently become the subject of public debate that presents different viewpoints. Regarding modern biotech innovations, we are going to discuss four main societal concerns revolve around ethical, public and laboratory safety, bioterrorism and environmental issues.

1) Ethical issues: Uncovering the human genome was a tremendous step forward for science, but the discovery created a series of new concerns ${ }^{4}$. Researchers have been able to use the information from the Human Genome Project to develop the new science of pharmacogentics, how an individual's genes affect his or her body's ability to metabolize or react to a drug. Modern pharmacogentics aims to eliminate adverse drug events (ADE) and side effects by tailoring drugs specific to a patient's genome. While the new personalized medications can eliminate side effects, the use of genetic information to create medicine contributes to the rising cost of drugs, and shifts attention away from designing affordable drugs available for mass population $^{4,5}$. Another burning issue is stem cell research. Supporters argue the embryos used to generate stem cell lines were going to be destroyed, and using them for research has the capacity to save untold numbers of lives. In contrast, opponents believe creating new lines from embryonic stem cells is akin to abortion, and the destruction of any embryo for research purposes is an ethical violation ${ }^{5}$. However, both sides have come to a partial agreement on the use of adult stem cells over embryonic cells, but functionally the adult cells offer far fewer options and less promising research ${ }^{4-6}$. Besides the age-old debate over whether cloning genes is sacrilegious, innumerable ethical questions arise over the appropriateness of licensing genetic inventions and other intellectual property issues ${ }^{5,7,8}$. In addition, it will most certainly go against the ethics of a significant number of science and professional societies as well existing laws of different countries. There are also other ethical concerns including when scientists use humans as clinical trial subjects - informed consent, confidentiality, wellbeing of the subjects, equal access to the benefits of research, compensation - have come into the table of discussion for decades ${ }^{4,5,7-9}$. Last but not the least, the concept of GM foods, its efficacy, acceptance and associated consumer rights, right to food, cost also have been debated ${ }^{4,5}$. 2) Public or laboratory safety or biosafety issues: Maintenance of laboratory safety or biosafety is a crucial point to ensure public safety. Human and laboratory safety issues are crucial as it is assumed that insects and plant-destroying bacteria or diseases will continue to evolve with the GMOs, resulting in superpests and superdiseases that are 
untreatable. Similar may happen with overconsumption of antibiotics, which are also GM products, and loss of their ability to fight off disease will result in rise of 'superbugs' ${ }^{10-12}$. Some new technologies, usually non-biologicals such as nanoparticles, make commercial production lines before they have been sufficiently tested for safety ${ }^{12}$. There is also concern about technician safety in laboratories even under secure conditions when working with organisms of unknown virulence. The public health danger posed by potentially pandemiccausing viruses or bacteria escaping from laboratories has become the subject of considerable discussion in public health sphere $^{12,13}$. The goal of biotech experiments, as researchers manipulate already-dangerous pathogens, is to produce vaccine or other remedies. However, outbreak of epidemics have already been experienced in course of history, due to faulty or erroneous handling of micro-organisms or chemicals ${ }^{12.13}$.

3) Bioterrorism: Biological weapons is not a myth anymore. In the recent past, the threat of a global bioterrorist attack has increased dramatically. In addition to the already existing microorganisms and techniques, the recent explosion in biotechnology has considerably added to the arsenal of the bioterrorist $^{4,14}$. Molecular biotechnologies are now much available which can be used by committed bioterrorist groups to manipulate and modify microorganisms and to make them increasingly infectious, virulent or treatment resistant for causing maximum casualties $^{14-17}$. Apart from that, research involving biological or chemical weapons necessarily involve exposures to toxic agents and levels of risk higher than those that exist in most research ${ }^{4,17}$. Such research would seem to compromise the core tenet of medical ethics that studies should not knowingly do harm. Indeed, the Environmental Protection Agency of the U.S. now refuses to accept toxicity tests done on human subjects to determine "safe levels"

4) Environmental issues: Environmental integrity remains a moral concern for environmentalists as they have predicted that biotechnology will promote the replacement of the natural environment with a purely artificial world and cause deprivation of healthy contact of human beings with nature $^{18,19}$. Recent controversies about genetically engineered crops have highlighted the need for experimental evidence and sound scientific judgment to assess the risks versus benefits. This concern is perhaps the most widely cited by those opposed to genetically modified organisms (GMOs). It is very difficult to predict what will happen in an ecosystem where a new organism has been introduced whether genetically modified or not. For example, if farmers introduce any herbicide-resistant marker into a plant, there is the possibility those traits may be transferred to a weed, making it resistant to herbicides as well ${ }^{19}$. The backlash against GMOs has been strong and is growing day by day. Opponents of GMOs claim the organisms actually put the entire food supply at risk through the homogenization of plant life and the death of biodiversity $^{18-21}$. They also argue that insects and plant-destroying bacteria or diseases will continue to evolve with the GMOs, resulting in superpests and superdiseases that are untreatable by modern methods ${ }^{18,19,21}$. Similarly, physicians, microbiologists, 
environmental scientists argue that GMOs include antibiotics that make their way into the human body. Overconsumption of antibiotics is harmful, as because those drugs lose their ability to fight off disease ${ }^{19}$.

\section{Regulations of Biotechnology and Public}

Policy: Societal issues are inevitably associated with regulation and public policy $^{22}$. Regulations and public policies are always fashioned in accordance with background assumptions or politically negotiated consensus about moral questions like "what is the public good? or who should make decisions and control events? or what are the fundamental purposes of government and society?"5 Even when tradition or consensus rules that individuals are to have complete discretion in exercising moral judgement (as is the case with respect to religious duties in most parts $)^{5}$. The purpose of public policies is to find a balance between safety regulation and innovation ${ }^{22}$. The two are not necessarily at odds: innovation has the potential to enhance safety, e.g. by replacing high-risk products with newer, safer products. Moreover, regulatory frameworks that are suitably designed and implemented have the potential to foster innovation; for example, fuel economy standards have improved the average fuel economy of E.U. and U.S. vehicles ${ }^{23}$. Thus, it is incorrect to assume that regulation inevitably creates barriers to innovation. However, one valid area of concern is that regulations have the potential to impede or delay the introduction of innovative products to the market, if the regulations add substantial up-front costs and delays to the process of developing and marketing a new product ${ }^{23}$. Hence, the regulatory process for the use of any biotech product should take into account both the risks and benefits of implementing that technology as well as the consequences of non-implementation and the viability of alternative technologies. As new biotechnology discoveries are made, many western governments develop regulations, legislation and guidelines to minimise risks to people and the environment ${ }^{23-27}$. Many governments have created environmental risk management bodies that regulates and manages risk concerning new products or organisms $^{23-27}$.

Conclusion: Biotech innovations are inevitable for upcoming days. If properly developed, biotechnology represents an opportunity for developing countries to realize tangible health and nutritional benefits, sustainable agriculture, green energy and other possibilities to eliminate hunger and poverty. The regulatory agencies must carry out regulatory functions to protect public health, ensure biosafety, prevent bioterrorism and environmental harms. However, the intent of the regulatory guidelines should be providing mechanisms to assess the safety of biotechnology products while simultaneously offering a framework for advancing innovation and increasing transparency, coordination, efficiency, and predictability. Many countries are actively developing this technology, and their support for biotechnology may turn the tide in global public acceptance in near future.

\section{References:}


1. Encyclopaedia Britannica. Biotechnology. Available from:

https:/www.britannica.com/technology/biotechn ology (Accessed December 17, 2017).

2. Verma AS, Agrahari S, Rastogi S, Singh A. Biotechnology in the realm of history. J Pharm Bioallied Sci. 2011;3(3):321-3.

3. DaSilva E, Baydoun E, Badran A. Biotechnology and the developing world. Electronic J Biotechnol. 2002;5(1):64-92.

4. Silverman E. The 5 most pressing ethical issues in biotech medicine. Biotechnol Healthc. 2004;1(6):41-6.

5. Macer DRJ. Biotechnology and Bioethics: What is Ethical Biotechnology? In: Brauer D. ed. Modern Biotechnology: Legal, Economic and Social Dimensions. Biotechnology. Vol.12. Weinheim: VCH; 1995.

6. Nurunnabi ASM. Prospects and problems of stem cell research in Bangladesh: can equity and justice be maintained in the context of public health demand? Eubios J Asian Int Bioethics: EJAIB. 2016;26(3):117-24.

7. Shapiro HT. Ethical and policy issues of human cloning. Science. 1997;277(5323):195-6.

8. La Montagne JR. Biotechnology and research: promise and problems. Lancet. 2001;358(9294):1723-4.

9. Kumar S. Biosafety and biosecurity issues in biotechnology research. Biosafety. 2015;4(1):e153.

10. Frommer W, Krämer P. Safety aspects in biotechnology - classifications and safety precautions for handling of biological agents. Arzneimittelforschung. 1990;40(7):837-42.

11. Gupta V, Sengupta M, Prakash J, Tripathy BC. Biosafety and bioethics. Basic and Applied Aspects of Biotechnology. 2016;503-20.

12. Pike RM. Past and present hazards of working with infectious agents. Arch Pathol Lab Med. 1978;102(7):333-6.

13. Coelho AC, Díez JG. Biological risks and laboratory-acquired infections: a reality that cannot be ignored in health biotechnology. Front Bioeng Biotechnol.2015;3:e56.

14. Moorchung N, Sharma AK, Mehta SR. Bioshock: biotechnology and bioterrorism. Med J Armed Forces India. 2009;65(4):359-62.
15. Noah DL, Huebner KD, Darling RG, Waeckerle JF. The history and threat of biological warfare and terrorism. Emerg Med Clin North Am 2002;20:255-71.

16. Zilinskas RA. Recombinant DNA Research and Biological Warfare. In: Zilinskas RA, Zimmerman BK, eds. The Gene Splicing Wars: Reflections on the Recombinant DNA Controversy. New York: Macmilian Publishers; 1986;167-203.

17. Caplan AL, Sankar P. Human subjects in weapons research. Science. 2002;298(5595):923.

18. McLean MR. The Future of Food: An Introduction to the Ethical Issues in Genetically Modified Foods. In: Khan AS. ed. Nanotechnology: Ethical and Social Implications. London: CRC Press; 2012.

19. Maghari BM, Ardekani AM. Genetically modified foods and social concerns. Avicenna J Med Biotechnol. 2011;3(3):109-17.

20. Heydari B, Razmkhah N. Intellectual property right of transgenic crops and right to work: Bioethical challenges in rural communities. Bangladesh J Bioethics. 2014;5(2):49-60.

21. Singh OV, Ghai S, Paul D, Jain RK. Genetically modified crops: success, safety assessment, and public concern. Appl Microbiol Biotechnol. 2006 A;71(5):598-607.

22. Fogleman V. Regulating science: an evaluation of the regulation of biotechnology research. Environmental Law. 1987;17(2):183-273.

23. National Academies of Sciences, Engineering, and Medicine (NASEM). The Current Biotechnology Regulatory System. In: Preparing for Future Products of Biotechnology. Washington DC: National Academies Press (US); 2017.

24. Health Canada. Health Canada's Role in the Regulation of Products from Biotechnology. 2008. Available from: https:/www.canada.ca/content/dam/hc$\mathrm{sc} / \mathrm{migration} / \mathrm{hc}-\mathrm{sc} / \mathrm{sr}$-sr/alt_formats/hpfbdgpsa/pdf/pubs/reg_bio_mod-eng.pdf (Accessed December 30, 2017).

25. Government New Zealand. Ministry for the Environment. Genetic modification in New Zealand. 2016. Available from: https:/www.mfe.govt.nz/publications/hazards/g 
m-nz-approach-jun04/genetic-modification-newzealand (Accessed December 28, 2017).

26. European Food Safety Authority (EFSA). GMO applications: regulations and guidance. Available from:

https:/www.efsa.europa.eu/en/applications/gmo/ regulationsandguidance (Accessed December 30, 2017).

27. UK Government. Health and Safety Executive. The Genetically Modified Organisms (Contained Use) Regulations 2014. Available from: https://www.hse.gov.uk/pubns/priced/129.pdf (Accessed December 29, 2017).

Authors' contribution: ASM Nurunnabi and M Mozaffor were involved in concept and design of the paper; ASM Nurunnabi, M Mozaffor, M Tabassum, TR Saikat, N Kabir and MA Hossain were equally involved in the literature search, review, compilation, manuscript writing and revision.

Conflict of interest: The authors report no conflicts of interest in this work. 